\title{
Optimal Placement of Off-Stream Water Sources for Ephemeral Stream Recovery
}

\author{
Matthew Rigge, ${ }^{1}$ Alexander Smart, ${ }^{2}$ and Bruce Wylie ${ }^{3}$ \\ Authors are ${ }^{1}$ Range Ecologist, Arctic Slope Regional Corporation Research \& Technology Solutions, Contractor to US Geological Survey (USGS) Earth \\ Resources Observation and Science (EROS) Center, Sioux Falls, SD 57198, USA; ${ }^{2}$ Professor, Department of Natural Resource Management, South \\ Dakota State University, Brookings, SD 57007, USA; and ${ }^{3}$ Research Physical Scientist, US Geological Survey (USGS) Earth Resources Observation and \\ Science (EROS) Center, Sioux Falls, SD 57198, USA.
}

\begin{abstract}
Uneven and/or inefficient livestock distribution is often a product of an inadequate number and distribution of watering points. Placement of off-stream water practices (OSWP) in pastures is a key consideration in rangeland management plans and is critical to achieving riparian recovery by improving grazing evenness, while improving livestock performance. Effective OSWP placement also minimizes the impacts of livestock use radiating from OSWP, known as the "piosphere." The objective of this study was to provide land managers with recommendations for the optimum placement of OSWP. Specifically, we aimed to provide minimum offset distances of OSWP to streams and assess the effective range of OSWP using Normalized Difference Vegetation Index (NDVI) values, an indicator of live standing crop. NDVI values were determined from a time-series of Satellite Pour l'Observation de la Terre (SPOT) 20-m images of western South Dakota mixed-grass prairie. The NDVI values in ephemeral stream channels (in-channel) and uplands were extracted from pre- and post-OSWP images taken in 1989 and 2010, respectively. NDVI values were normalized to a reference imagine and subsequently by ecological site to produce nNDVI. Our results demonstrate a significant $(P<0.05)$ increase in the nNDVI values of in-channel vegetation within $1250 \mathrm{~m}$ of OSWP following their implementation. The area of piospheres $(n=9)$ increased with pasture size $\left(R^{2}=0.49, P=0.05\right)$ and increased with average distance to OSWP in a pasture $\left(R^{2}=0.43, P=0.07\right)$. Piospheric reduction in nNDVI was observed within $200 \mathrm{~m}$ of OSWP, occasionally overlapping in-channel areas. The findings of this study suggest placement of OSWP 200 to $1250 \mathrm{~m}$ from streams to achieve optimal results. These results can be used to increase grazing efficiency by effectively placing OSWP and insure that piospheres do not overlap ecologically important in-channel areas.
\end{abstract}

Key Words: ephemeral streams, livestock grazing, NDVI, off-stream water, piosphere, riparian zones

\section{INTRODUCTION}

Water sources have been commonly cited as the most critical factor in determining livestock grazing patterns (e.g., Bailey 2005). The distribution of water, forage, and livestock grazing in rangelands are spatially heterogeneous, leading to uneven forage utilization. In relatively flat New Mexico terrain, Valentine (1947) reported that forage utilization was $50 \%$ at 0 to $0.8 \mathrm{~km}$ from water sources, $30 \%$ at $1.6 \mathrm{~km}$, and $12 \%$ at $3.2 \mathrm{~km}$. Gillen et al. (1984) observed that livestock preferentially grazed areas within $200 \mathrm{~m}$ of water sources, leading to the degradation of riparian vegetation and elevated erosion rates (Sandercock et al. 2007), and inefficient forage utilization.

To address these issues, a variety of best management practices (BMPs) have been implemented. One BMP involves making off-stream water sources (OSWP) available to livestock in pastures. OSWP have been reported to alter livestock habitat preference (Launchbaugh and Howery 2005), draw livestock away from riparian areas and streams, improve stream water quality, and increase ranch profitability by improving livestock

\footnotetext{
Research was funded by the USDA Conservation Effects Assessment Project (CEAP) 2009-51130-06014 and USGS Climate and Land Use Program Research and Development Program.

Correspondence: Matthew Rigge, US Geological Survey Earth Resources Observation and Science Center, 47914 252nd St, Sioux Falls, SD 57198, USA. Email: mrigge@usgs.gov

Manuscript received 9 August 2012; manuscript accepted 15 January 2013.
}

(c) 2013 The Society for Range Management distribution and weight gains (Porath et al. 2002; DelCurto et al. 2005). Alternate strategies to draw livestock away from riparian areas such as the placement of minerals or supplements in uplands and herding have potential, but are typically less successful than OSWP (Porath et al. 2002; Bailey 2004).

Grazing intensity (i.e., forage utilization rate) decreases with distance from OSWP (James et al. 1999), because the potential grazing area decreases as a function of distance to OSWP and due to the natural draw of livestock to water sources (Bailey 2005). In arid/semiarid regions where natural water sources are limited, a utilization gradient radiating from OSWP often develops (Valentine 1947), referred to as a "piosphere" (James et al. 1999; Graz et al. 2012; Shahriary et al. 2012). Range condition, biomass production, live standing crop, vegetation cover, erosion, soil compaction (Thrash and Derry 1999; Matney 2010), and plant species diversity (Andrew 1988) are often related to OSWP proximity. Consequently, live standing crop was found to increase with distance from OSWP (Fusco et al. 1995; Shahriary et al. 2012). Conversely, bare soil cover (Augustine et al. 2012) and erosion potential (James et al. 1999) were found to decrease with distance from OSWP. These patterns frequently result from livestock spending time chewing cud and resting near OSWP (Thrash and Derry 1999), and from the extended grazing season facilitated by OSWP (Graz et al. 2012).

The most heavily utilized portion of the piosphere has been referred to as the sacrifice zone in which grazing pressure significantly reduces live standing crop (Shahriary et al. 2012). 
In Australia, sacrifice zones radiating $500 \mathrm{~m}$ from watering points were reported; in this zone the soil crust was broken, and percent of bare soil cover and erosion were high (James et al. 1999). This zone is often dominated by unpalatable, trampleresistant "increaser" species, because of the selective grazing of palatable species and trampling (James et al. 1999; Matney 2010; Shahriary et al. 2012). Land managers should therefore consider the ability of OSWP to restore riparian areas and improve grazing distribution, while also recognizing the potential of sacrifice zone/piosphere-related degradation prior to their implementation (Andrew 1988).

Little attention has been given to the optimum placement of OSWP, which is critical to achieving the desired results of riparian recovery and nonpoint source pollution reduction through improved grazing distribution (Gillen et al. 1984; Senft et al. 1985; Bear et al. 2012). Optimum placement of OSWP is a critical issue, due to the ecological importance of riparian areas for wildlife habitat and water quality (George et al. 2011), and the large number of OSWP installed. For example, the Natural Resources Conservation Service (NRCS) funded the installation of 127000 watering facilities on private land in the western United States from 2004 to 2007 (Toombs and Roberts 2009).

Uneven and/or inefficient livestock distribution is often a product of inadequate number and distribution of watering points (Andrew 1988; Shahriary et al. 2012), so effective placement of OSWP is a key consideration in rangeland management plans and health (Matney 2010). Unfortunately, there is a lack of quantitative soil and vegetation data in relation to OSWP (Matney 2010). The objective of this study was to remotely detect the influence of OSWP implementation on in-channel (here defined as 0 to $20 \mathrm{~m}$ from stream centerline) and upland live standing crop at stratified distances to OSWP, and use these data to provide land managers with recommendations for the optimum placement of OSWP to improve in-channel vegetation, grazing distribution, and minimize the impacts of piospheres (Shahriary et al. 2012). This quantitative information can be used to insure that piospheres surrounding OSWP do not overlap ecologically critical (Sandercock et al. 2007; George et al. 2011) in-channel and riparian areas. Further, the efficiency of OSWP can be increased by reducing overlap between the effective ranges of OSWP (Matney 2010).

\section{STUDY SITE DESCRIPTION}

The study area (lat $43^{\circ} 56^{\prime} \mathrm{N}$, long $102^{\circ} 12^{\prime} \mathrm{W}$ ) is located near Wall, South Dakota and the headwaters of the Bad River in western South Dakota (Fig. 1). The streams in the study area are ephemeral with channel widths ranging from $<1 \mathrm{~m}$ to 10 $\mathrm{m}$. Data from a study area stream for the growing seasons (April-September) of 1999-2004 indicated that flow above zero occurred in $28 \%$ of observations. Most streams originate in the higher relief badlands, but the majority of their course is in clayey and/or silty flatlands with minimal relief (Fig. 1). Streams are generally moderately sinuous and incised $1 \mathrm{~m}$ to 2 $\mathrm{m}$. The study area is managed by the US Forest Service Buffalo Gap National Grassland. Evaluated pastures $(n=4)$ ranged from 479 ha to 1942 ha in size and totaled 3712 ha. During

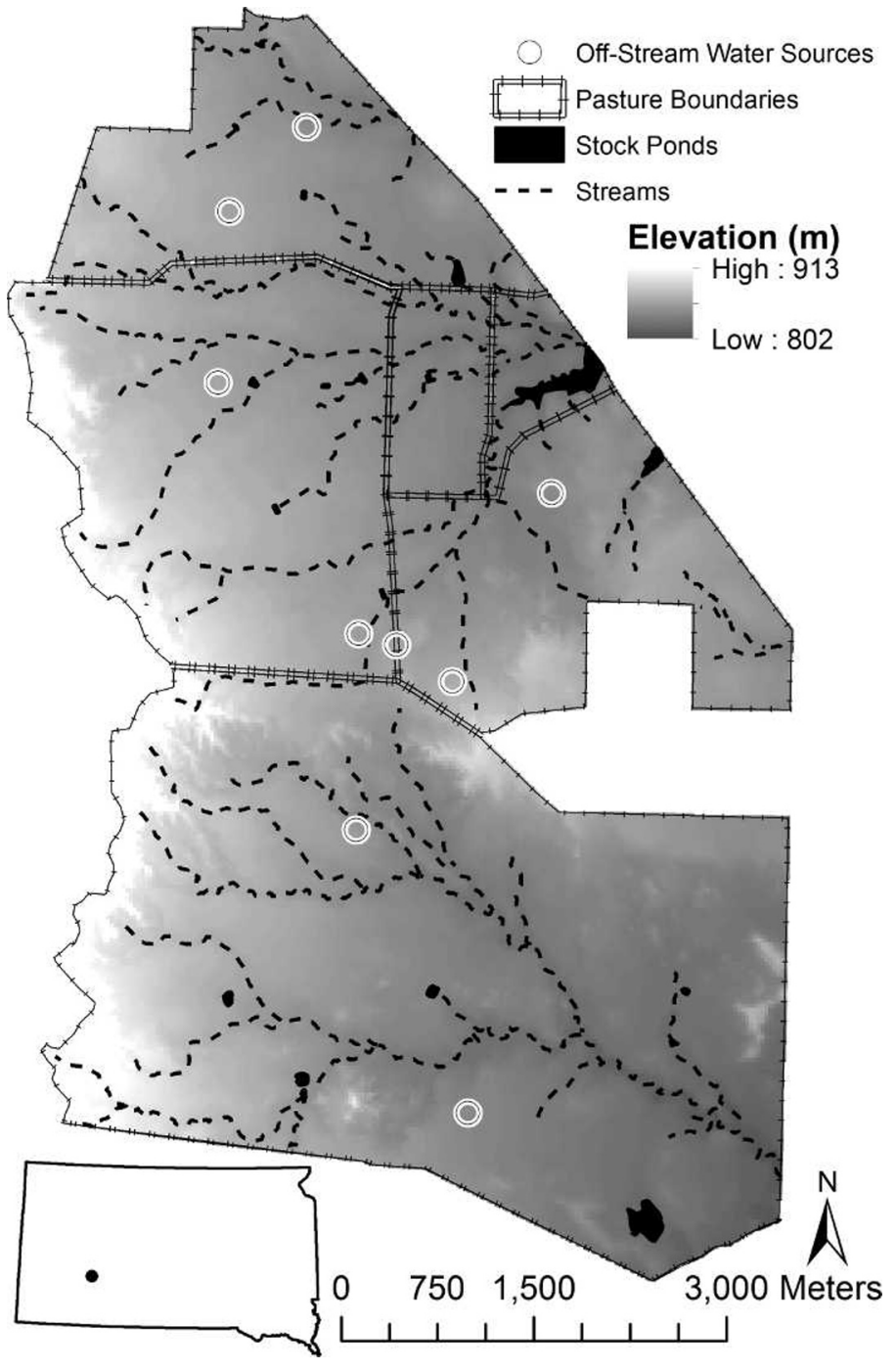

Figure 1. Study area pasture boundaries, ephemeral stream channels, stock ponds, and off-stream water practices (OSWP). Inset map shows the location of the study area in western South Dakota, USA.

the grazing season (May through October), pastures were grazed once-over as part of a six pasture rotation, with an average stocking rate of $0.67 \mathrm{AUM} \cdot \mathrm{ha}^{-1}$, using yearling steers (Bos taurus). Grazing occurred from 1 July to 15 August or 16 August to 30 September, alternating periods yearly.

Conservation practices, consisting of cross fencing and installation of water pipelines with nine OSWP (with the water coming from a municipal source) were implemented in 1991. Prior to 1991, the study area was managed as single pasture, with season-long continuous grazing, at a rate of 0.65 to 0.70 AUM $\cdot{ }^{-1}$. Each of the four evaluated pastures had at least one OSWP installed; two pastures with two OSWP (each) and two pastures with two OSWP (each), with an additional OSWP shared between these pastures (Fig. 1). Several sediment control structures and $1 \mathrm{~km}$ of riparian exclusion fencing were also constructed; however, these areas were excluded from analysis because OSWP were the focus of this study. In addition to the OSWP, livestock utilized several stock ponds and likely used pools of water in stream channels when available (Fig. 1). Because these alternate sources of water remained consistently 
available throughout the study period (none were added or eliminated) and therefore had a constant potential to influence livestock distribution, we consider the addition of OSWP as the experimental treatment. Additionally, seasonal sources of water are less likely to be the focus of livestock use than OSWP (Thrash 1998). Hereafter, the period following the implementation of the OSWP will be referred to as the post-OSWP period.

The study area contains steep badland formations in addition to relatively flat rangelands interspersed with streams. These formations and the surrounding soils are composed of gray and white loam, silty loam, and silty clay loam. Although some areas are nearly devoid of vegetation, most is vegetated (Barker and Whitman 1988). Western wheatgrass (Pascopyrum smithii [Rydb.] Á. Löve) is the dominant species; other cool season grasses included needle-and-thread (Hesperostipa comata [Trin \& Rupr.] Barkworth) and green needle grass (Stipa viridula [Trin.] Barkworth). Buffalo grass (Bouteloua dactyloides [Nutt.] J T. Columbus), blue grama (Boutelona gracilis [Willd. ex Kunth] Lag. ex Griffiths), and sideoats grama (Bouteloua curtipendula [Michx.] Torr.) are the dominant warm season grasses (Barker and Whitman 1988). Herbaceous in-channel vegetation includes prairie sandreed (Calamovilfa longifolia [Hook.] Schribn.), switchgrass (Panicum virgatum L.), foxtail barley (Hordeum jubatum L.), sedges (Carex spp.), cocklebur (Xanthium strumarium L.), and American licorice (Glycyrrhiza lepidota Pursh). The in-channel area also can include species considered to be riparian (e.g., sandbar willow [Salix exigua Nutt.]) or upland (e.g., sideoats grama and western wheatgrass) because the ephemeral nature of streams enables colonization of these species near the stream channel (Senft et al. 1985). Field observations during 18 to 22 July, 2011 suggested that species composition near OSWP included a higher proportion of increaser annual species, similar to that reported by Matney (2010); however, no species composition field data were collected.

The study area climate is strongly continental, with daily mean temperatures ranging from $32^{\circ} \mathrm{C}$ in July to $-14^{\circ} \mathrm{C}$ in January, and a yearly mean of $8^{\circ} \mathrm{C}$ (Smart et al. 2007). The growing season averages 115 to $130 \mathrm{~d}$ in length. Precipitation in the semiarid study area averages $398 \mathrm{~mm} \pm 25 \mathrm{~mm}$ (1 SE), of which $80 \%$ occurs during the growing season from April to September.

\section{METHODS}

\section{Imagery}

We used Satellite Pour l'Observation de la Terre (SPOT) L1A multispectral high resolution visible (HRV) satellite imagery from SPOT 1, 4, and 5. Images from SPOT 1 and 4 sensors had $20-\mathrm{m}$ spatial resolution, whereas SPOT 5 had $10-\mathrm{m}$ spatial resolution that was resampled to $20 \mathrm{~m}$ using the nearestneighbor method (to match the spatial resolution of SPOT 1 and 4). Images were reprojected to Albers Equal Area, and Normalized Difference Vegetation Index (NDVI) values were calculated using ERDAS IMAGINE (Intergraph, Madison, AL). The NDVI represents photosynthetic potential and has been strongly correlated with aboveground live standing crop (Wylie et al. 2002; Kawamura et al. 2005). The NDVI values were extracted from pre-OSWP (3 August and 24 August 1989) and post-OSWP (16 July and 18 August 2010) images (CNES, Distribution Spot Image, Paris, France). Late-summer images were used because the difference in live standing crop between in-channel and upland areas was greatest in this typically dry period of the growing season; most upland species are cool season $\left(\mathrm{C}_{3}\right)$ and are senesced during this period, whereas most in-channel species are warm season $\left(\mathrm{C}_{4}\right)$ and are actively growing (Vande Kamp et al. 2013). This has the effect of amplifying the in-channel vegetation signal relative to uplands, and maintaining similar phenological conditions between years. Yearly precipitation was 323 and $388 \mathrm{~mm}$ in 1989 and 2010, respectively. Pre- and post-OSWP image pairs were averaged to generate the mean NDVI of each time period. Averaging of the image pairs was done to reduce the likelihood of contamination by atmospheric effects and to better represent the actual conditions present during each period. All images were clear, and cloud cover was not present.

Normalization of Imagery. The NDVI values of the study area were normalized by subtracting each pixel value from the mean NDVI in each image (clipped to the study area boundary) and dividing by the standard deviation. Normalized NDVI values $<1$ indicate a below-average NDVI; alternatively, values $>1$ indicate an NDVI above the mean (Vande Kamp et al. 2013). Hereafter, normalized NDVI values will be referred to as nNDVI. Although the range of NDVI values is bounded by -1 and +1 , the normalization process extends the range of nNDVI to include values greater than 1 . Instances in which nNDVI values are negative occur when original NDVI values were $<0$. An important property of the nNDVI is that the sum of changes through time equals zero (i.e., $\Sigma \Delta \mathrm{nNDVI}=0$ ).

Normalization of imagery was required because we used multiple SPOT sensors and also because of variable atmospheric conditions and solar illumination at each image date (El Hajj et al. 2008). Normalization reduces atmospheric effects and focuses attention on actual changes to ground conditions (Eckhardt et al. 1990). Normalized NDVI values have been tightly linked to NDVI values obtained following an atmospheric correction (El Hajj et al. 2008). Atmospheric correction though dark object subtraction such as the Chavez COST (Chavez 1996) can be useful, but require radiative transfer codes (El Hajj et al. 2008). Deterministic approaches, such as that used by Eckhardt et al. (1990) should be used in large study areas where differences in view angle between east- and west-looking SPOT images increases atmospheric contamination (Moran et al. 1990). Due to the small size of the current study area, differences in view angle are negligible, and a simpler method of normalization is suitable.

We used pseudo-invariant pixels $(n=100)$ located on large $(>2 \mathrm{ha})$ areas of bare ground to insure our normalization procedure was appropriate. A paired two-sample (two-sided) $t$ test was used to evaluate any differences in the nNDVI of the pseudo-invariant pixels between the pre- and post-OSWP period. The mean nNDVI of bare ground (pseudo-invariant) pixels did not statistically differ between images $(P=0.78)$, indicating that the normalization procedure was successful. Moreover, absolute live standing crop estimates (e.g., kg live biomass $\cdot \mathrm{ha}^{-1}$ ) were not the focus of this study; rather, we focused on the relative abundance of live standing crop of 
upland and in-channel vegetation at stratified distances to OSWP.

\section{Normalization by Ecological Site}

Differences in the in-channel vegetation at specified distances from OSWP could be biased by differences between locations related to ecological sites (i.e., a badlands ecological site that existed $1000 \mathrm{~m}$ from an OSWP could not be accurately compared to a loamy ecological site at the same distance). Correspondingly, the most important assumption of piosphere gradient analysis is that all sample points represent the same ecological site (Hosten 1995). Normalization by ecological site therefore was necessary to avoid bias in soils and plant communities, and to address the nonuniform suitability of sites to grazing (Graz et al. 2012) and nonuniform live standing crop. The Soil Survey Geographic (SSURGO) ecological site data for the study area were downloaded from the NRCS Soil Data Mart, and the average nNDVI in each ecological site $(n=9)$ was determined. Ecological site average nNDVI values ranged from 0.18 for badlands to 1.45 for loamy soils. The nNDVI values within each ecological site were normalized by subtracting each pixel value by the mean nNDVI in its respective ecological site and dividing by the standard deviation, so that the average nNDVI of each ecological site equaled 1. This approach minimizes differences in nNDVI related to ecological site. The nNDVI is a relative indicator of live standing crop, normalized for interannual variation associated with weather and ecological site conditions. Normalization by image mean reduces the influence of weather differences between the pre- and post-OSWP period, clarifying the influence of OSWP on live standing crop abundance, whereas normalization by ecological site mean allows the analysis of live standing crop by distance to OSWP.

\section{In-Channel Vegetation}

First- to fourth-order stream channels (total length $=75 \mathrm{~km}$ ) were digitized in ArcGIS using 2010 National Agriculture Imagery Program (NAIP) imagery. The vertices of the digitized stream channels were converted to points $(n=3125)$ which were subsequently used to extract nNDVI from the pre- and post-OSWP periods. These data are used to evaluate the influence of OSWP implementation on in-channel areas, and the effect of distance from OSWP on this relationship. Because all stream channels were less than $20 \mathrm{~m}$ in width, the $20-\mathrm{m}$ SPOT imagery includes riparian vegetation in addition to inchannel vegetation. Despite this limitation, Vande Kamp et al. (2013) reported that $20 \mathrm{~m}$ SPOT imagery was proficient at detecting in-channel vegetation establishment in western South Dakota ephemeral streams. Moreover, the condition of riparian vegetation and adjacent upland vegetation is tightly linked with the in-channel vegetation and functionality.

\section{Upland Vegetation}

To determine the influence of OSWP on upland vegetation, stratified random sample points $(n=9230)$ were placed 0 to $1000 \mathrm{~m}$ from OSWP. Points were used to extract SPOT nNDVI values from the pre- and post-OSWP periods. The nNDVI values from the pre- and post-OSWP periods were used to infer the grazing pressure at given distances to OSWP with the premise that a decrease in nNDVI from the pre- to post-OSWP period near the OSWP was a result of higher grazing pressure (Bastin et al. 1993). Similarly, an increase in nNDVI from the pre- to post-OSWP period was interpreted as a decrease in grazing pressure. We defined piospheres as the area immediately surrounding OSWP where significant $(P<0.05)$ reductions in nNDVI occurred between the pre- and post-OSWP period, presumably due to increased grazing pressure. We recognize that piospheres are grazing gradients radiating from OSWP (James et al. 1999; Shahriary et al. 2012) that are likely more extensive than our definition. Field observations suggested that conditions near OSWP were not consistent with previous definitions of sacrifice zones (James et al. 1999; Shahriary et al. 2012), suggesting that "piosphere" was the appropriate terminology. Although no field data of standing crop surrounding OSWP were collected, Bastin et al. (1993) demonstrated highly significant correlations between remotely sensed and field data in piospheres. Further, the NDVI maintains its sensitivity to changes in live standing crop at low levels (Wylie et al. 2002).

\section{Statistical Analysis}

The pre- and post-OSWP average nNDVI at each in-channel and upland sample location was determined and regressed against stratified Euclidean distance to nearest OSWP in its respective pasture (i.e., constrained by fencelines), using leastsquares linear regression. The average nNDVI at each distance to OSWP class (for both in-channel and upland areas) was compared using a paired two sample (two-sided) $t$ test, with $P<0.05$ considered significant. Radii of piospheres surrounding $\operatorname{OSWP}(n=9)$ were evaluated with least-squares linear regression, using pasture size, number of OSWP within a pasture, and average distance to OSWP within a pasture as independent variables (each independent variable was assessed by itself). Multiple regression analysis was not used to evaluate factors influencing piosphere radii because the resulting model would be specific to the pasture size and ecological sites of our study area.

\section{RESULTS AND DISCUSSION}

\section{Effective Range of Off-Stream Water Practices}

In the pre-OSWP period, the nNDVI (reported to increase with live standing crop; Wylie et al. 2002; Kawamura et al. 2005) of in-channel areas was not significantly related to distance to the location of OSWP (yet to be installed) $\left(R^{2}=0.28 ; P=0.15\right.$; $\mathrm{Y}_{0}[\mathrm{Y}$-intercept $\left.]=0.92\right)$, but tended to increase with distance from OSWP (Fig. 2). In the post-OSWP period, the reverse was the case because the in-channel nNDVI decreased linearly with distance to OSWP $\left(R^{2}=0.68 ; P=0.013 ; \mathrm{Y}_{0}=1.22 ;\right.$ Fig. 2$)$. The overall result was a statistically significant increase in the nNDVI of in-channel areas within $1250 \mathrm{~m}$ of OSWP in the post-OSWP period. The concentration of significantly increased in-channel nNDVI near OSWP suggests that the changes between the pre- and post-OSWP periods were associated with OSWP development. Moreover, the average in-channel nNDVI significantly decreased $(P<0.05)$ in adjacent pastures where OSWP were not developed (data not 


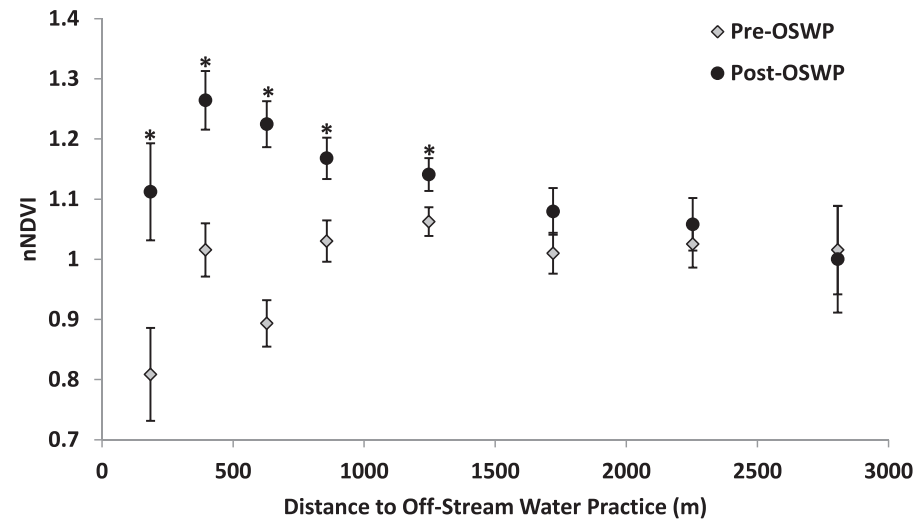

Figure 2. Mean normalized NDVI (nNDVI) and SE of in-channel areas at classified distances from off-stream water practices (OSWP) during preOSWP and post-OSWP periods in western South Dakota ephemeral streams. Pre-OSWP data is from 3 August and 24 August 1989 images and post-OSWP data is from 16 July and 18 August 2010 images. Distance classes marked with an asterisk indicate a significant $(P<0.05)$ difference between pre- and post-OSWP nNDVI.

shown), providing further evidence that the increased nNDVI was associated with OSWP. The influence of OSWP on inchannel vegetation was negligible beyond $1250 \mathrm{~m}$ (corroborating work by Valentine [1947]), and their effectiveness decreased with distance, as demonstrated in previous work (Bailey 2005). The increase in the in-channel nNDVI demonstrated the effect of OSWP in presumably altering livestock habitat preference to improve grazing distribution (Launchbaugh and Howery 2005) by reducing grazing heterogeneity and decreasing in-channel grazing pressure, both critical to a well-managed rangeland (Senft et al. 1985).

The nNDVI of in-channel zones within $1250 \mathrm{~m}$ of OSWP were significantly higher in the post-OSWP period (Fig. 2). However, the area within $250 \mathrm{~m}$ of OSWP had a lower nNDVI (in the post-OSWP period) than expected by its location (i.e., the linear regression between distance to OSWP and nNDVI would predict the nNDVI within $250 \mathrm{~m}$ of OSWP to be higher than the observed value of 1.1). This pattern was likely due to the high grazing pressure and trampling near OSWP (Gillen et al. 1984) extending into in-channel areas. Nevertheless, the inchannel nNDVI $0 \mathrm{~m}$ to $250 \mathrm{~m}$ from OSWP (in the post-OSWP period) was still significantly higher than in the pre-OSWP period. When the area within $250 \mathrm{~m}$ of OSWP was excluded, the strength of the negative relationship between distance to OSWP and in-channel nNDVI in the post-OSWP period was stronger $\left(R^{2}=0.96 ; P<0.01\right)$ than when this area was included. This pattern suggested that the ability of OSWP to reduce in-channel grazing pressure was strongest $250 \mathrm{~m}$ to $1250 \mathrm{~m}$ from OSWP. Although a previous study (WashingtonAllen et al. 2004) did not detect the extension of piospheres into riparian areas in Utah shrublands, our results indicated that piospheres, as indicated by nNDVI, can extend into inchannel and riparian areas when grazed by livestock in situation similar to those observed during this study.

\section{Piospheres}

In the pre-OSWP period, the nNDVI of upland vegetation had a tendency to decrease with distance to (future) OSWP

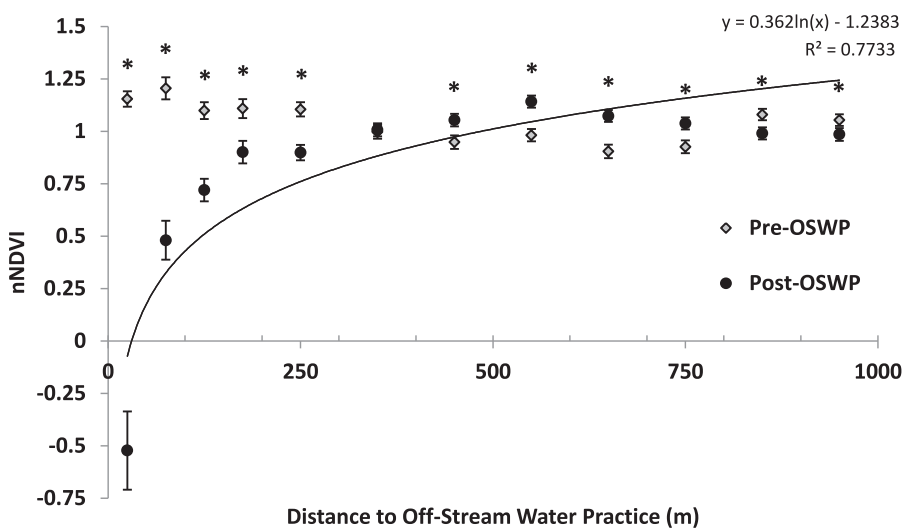

Figure 3. Effect of distance to off-stream water practices (OSWP) on the mean normalized NDVI (nNDVI) of surrounding upland vegetation in western South Dakota. Results are a pooled average of nine OSWP. Error bars are \pm 1 SE. Distance classes marked with an asterisk indicate a significant $(P<0.05)$ difference between pre- and post-0SWP nNDVI. Post-OSWP points are fit by a logarithmic regression.

$\left(R^{2}=0.36 ; P=0.06\right.$; Fig. 3$)$. Following OSWP implementation, the nNDVI of upland vegetation increased logarithmically $\left(R^{2}=0.77 ; P<0.01\right)$ with distance from OSWP, a pattern often followed by piospheric processes (Thrash and Derry 1999). This pattern corresponded with the normal permanent piosphere gradient described by Pickup et al. (1994), suggesting an increase in forage utilization near OSWP. The post-OSWP nNDVI in piospheres was reduced $20 \%$ compared to preOSWP conditions at $250 \mathrm{~m}$ from OSWP and was reduced $145 \%$ at $25 \mathrm{~m}$ (Fig. 3). Overall, the upland nNDVI at $0 \mathrm{~m}$ to $250 \mathrm{~m}$ from OSWP was significantly lower in the post-OSWP period, whereas the nNDVI $450 \mathrm{~m}$ to $850 \mathrm{~m}$ from OSWP was significantly higher compared to the pre-OSWP period. The dramatic increase in grazing pressure near OSWP in the postOSWP period (as evidenced by the reduced nNDVI signal) corroborates work by Senft et al. (1985), who found the duration of livestock grazing near an OSWP was 95\% greater than that expected by its area, indicating that OSWP do alter livestock grazing patterns (Launchbaugh and Howery 2005). The increased amount of rainfall received in the post-OSWP period $(388 \mathrm{~mm}$ ) compared to the pre-OSWP period $(323 \mathrm{~mm})$ would be expected to proportionally reduce the impacts of livestock grazing presence near OSWP (Bastin et al. 1993; Hosten 1995). The lack of such a pattern further demonstrates that the normalization procedure of the current study was successful, and that the reduced nNDVI observed around OSWP was associated with their implementation.

OSWP in the study area had piospheres ranging from $50 \mathrm{~m}$ to $350 \mathrm{~m}$ in radius and averaged $200 \mathrm{~m}$, as indicated by reduced $(P<0.05)$ upland nNDVI from the pre- to post-OSWP period (Figs. 3 and 4), similar to that seen with in-channel vegetation (Fig. 2) and previous work (Gillen et al. 1984). Rugged topography and other barriers can alter livestock distribution patterns and reduce the function of OSWP; however, the current study area is relatively flat (Fig. 1), and these factors were likely a minor factor affecting vegetation utilization rates (Bailey 2005) and piosphere radii (Gillen et al. 1984). Our 200$\mathrm{m}$ average piosphere radii values correspond with the findings of Bailey et al. (2004) who found that livestock spent nearly 


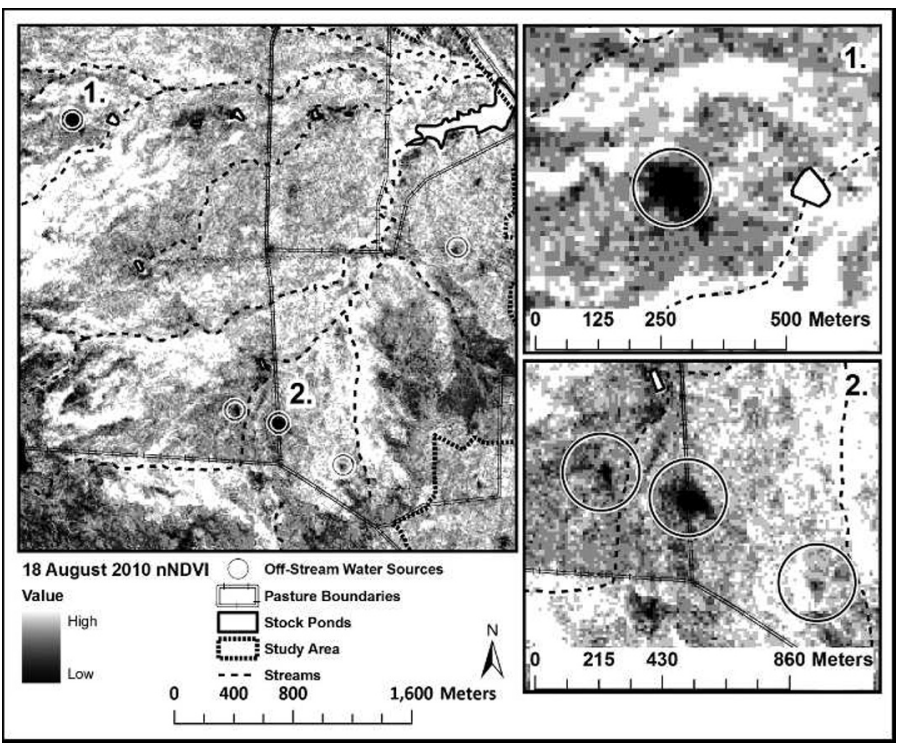

Figure 4. Examples of piospheres occurring around off-stream water practices (OSWP) $19 \mathrm{yr}$ after implementation in a portion of the western South Dakota study area. Areas (1 and 2) shown in the left panel are expanded in the right panels. The 18 August 2010 SPOT 4 nNDVI image with $10-m$ resolution is displayed.

$8 \mathrm{~h} \cdot \mathrm{d}^{-1}$ within $200 \mathrm{~m}$ of OSWP. When near OSWP, livestock often lie down and chew cud (Thrash and Derry 1999; Bailey et al. 2004). Therefore, the reduced nNDVI was mostly a result of trampling, not grazing.

The largest post-OSWP nNDVI SE was within $100 \mathrm{~m}$ of OSWP, indicating that vegetation cover percentage and livestock forage use in piospheres was highly variable (Fig. 3 ). Piospheres averaged $12.5 \mathrm{ha} \cdot \mathrm{OSWP}^{-1}$, totaling $112.5 \mathrm{ha}$, or $3 \%$ of the study area. The piospheres found in the current study were much smaller than those reported by James et al. (1999), who found zones that were $2 \mathrm{~km}$ to $3 \mathrm{~km}$ in radius in Australia. In regions such as interior Australia with large pastures, the area of piospheres have been found to be greater, a combined result of the greater number of livestock on the large pastures, and the uneven usage of pastures (James et al. 1999; Thrash and Derry 1999).

The radii of piospheres increased with pasture size $\left(R^{2}=0.49 ; P=0.05\right)$, with average distance to OSWP in a pasture $\left(R^{2}=0.43 ; P=0.07\right)$, and with pasture area (ha) per OSWP $\left(R^{2}=0.47 ; P=0.06\right)$, but was unrelated to the number of OSWP in a pasture $\left(R^{2}=0.19 ; P=0.28\right)$. Uneven livestock distribution often is a product of inadequate number and distribution of watering points (Andrew 1988; Shahriary et al. 2012) and pasture size, both large (Barnes et al. 2008) and small (Bear et al. 2012). Accordingly, in commercial-size pastures, grazing heterogeneity often increases with pasture size (Senft et al. 1985), leading to the positive relationship we observed between pasture size and piosphere radius. Improved livestock performance often has been linked with reduced pasture size and distance to OSWP, both of which increase the uniformity and overall usage of forage (Hart et al. 1993; Barnes et al. 2008). In small pastures ( $<70 \mathrm{ha})$, however, riparian grazing pressure was reported to decrease with pasture size (Bear et al. 2012), inferring the existence of an optimal pasture size for reducing riparian grazing pressure. Pastures within the study area were large (hundreds of ha in size), so the radii of piospheres were likely more related to total animal unit months (AUMs) than pasture size.

Our analysis provided each point in a pasture a specific distance to the nearest OSWP within that pasture; however, distance to OSWP assumes that piospheres are free to develop evenly in all directions around each OSWP (Graz et al. 2012). In reality, the extension of several study area piospheres might have been physically constrained by the presence of fencelines near the OSWP (Figs. 1 and 4). This would focus grazing pressure on the portion of the concentric area around OSWP not constrained by fencelines, thereby decreasing nNDVI at a further distance from OSWP than in an unconstrained situation. Figure 4 displays no evidence of this pattern, presumably because OSWP have a stronger influence on grazing intensity than that of fencelines (Graz et al. 2012).

\section{Piosphere Patterns}

Examples of piospheres ( $n=5$ out of nine in the study area) occurring in the study area are displayed in Figure 4. The piospheres are apparent as areas of reduced nNDVI surrounding OSWP; the radii of piospheres varied by management and accessibility to livestock. One of the piospheres in panel two of Figure 4, for example, was shared between two pastures and correspondingly had a greater radius than the piospheres of the two adjacent (unshared) OSWP. Although it might be economical to place an OSWP along a fenceline to enable use from multiple pastures, doing so increases the grazing pressure and subsequently the likelihood and extent of piosphere formation, especially in large pastures. Piospheres were frequently skewed toward in-channel areas (Figs. 2 and 4), due to the presence of water, shade, and forage (Bailey 2005; Launchbaugh and Howery 2005). Because bare soil (Augustine et al. 2012) and soil nutrient levels (Matney 2010; Shariary et al. 2012) are higher in piospheres, their extension into inchannel areas represents a threat to bank stability stream and water quality.

\section{Effective Placement of Off-Stream Water Practices}

Although some degree of degradation can be expected around OSWP due to the concentration of grazing pressure (James et al. 1999; Shahriary et al. 2012), numerous recommendations for ecologically appropriate placement can be drawn from the current study and the literature that can minimize impacts. Increased in-channel nNDVI was evident within $1250 \mathrm{~m}$ of OSWP in the post-OSWP period (Fig. 2) and piospheres existed in upland and in-channel areas within an average of $200 \mathrm{~m}$. Therefore, in the study area and ecological sites we examined, OSWP should be located between 200 and $1250 \mathrm{~m}$ from the nearest stream; however, these distances will vary with pasture size. Placement of OSWP beyond $1250 \mathrm{~m}$ of a stream may result in livestock using the OSWP as a supplemental, not replacement, water source. These recommendations would tend to reduce in-channel grazing pressure near the OSWP, yet provide enough incentive for livestock to use the OSWP as opposed to a stock pond or stream. Placement of OSWP away from streams is critical to ensure minimal overlap of piospheres into sensitive in-channel areas (Sandercock et al. 2007; George et al. 2011; Fig. 2), and also promotes improved grazing 
evenness (Valentine 1947; Senft et al. 1985). Additionally, the effective ranges $(1250 \mathrm{~m})$ of two OSWP would overlap if placed less than $2500 \mathrm{~m}$ apart, in which case the OSWP effect would be saturated. Our data indicate that OSWP can be placed closer together than the recommended minimum distance of $5 \mathrm{~km}$ (Matney 2010) in southeastern Oregon. This highlights the site-specific nature of our results and other piosphere studies (i.e., specific distance recommendations, which are largely a function of pasture size), even though piospheric processes are generally similar between sites.

Placement of OSWP depends on the desired management outcome. If management priorities include maximizing diversity and ecosystem function, OSWP placement would be uneven, and allow a diversity of grazing impacts, including lightly/ungrazed areas (Thrash and Derry 1999). If maximizing livestock production were the primary management concern, an even distribution of OSWP across pastures would achieve the most efficient forage utilization. This recommendation holds for pastures without in-channel areas; however, our results suggest that the even distribution might need to be interrupted when in-channel areas are present. Placement of OSWP in areas with vegetation of low to moderate palatability will result in an increase in the use of this resource, while also insuring that highly palatable vegetation is not overgrazed (Graz et al. 2012), thereby increasing grazing evenness.

Because the high grazing intensity near OSWP (Figs. 2 and 3) can lead to the potential of increased bare soil (Thrash and Derry 1999; Augustine et al. 2012), coinciding with elevated runoff rates (Sandercock et al. 2007), OSWP should not be located on highly erodible soils and steep slopes. Additionally, sites with an abundance of clay and silt are susceptible to compaction in the piosphere (Thrash and Derry 1999), so OSWP placement in these sites should be avoided. To achieve the desired results of in-channel/riparian recovery and improved grazing evenness, placement of OSWP must take into consideration the distribution patterns and grazing preferences of livestock (Senft et al. 1985; Bailey 2005; DelCurto et al. 2005; Launchbaugh and Howery 2005) by providing an adequate number and distribution of OSWP (Andrew 1988). Additional benefits associated with increased grazing evenness included the protection of fisheries, wildlife, and vegetation resources that are abundant in in-channel and riparian areas (Bailey 2004). The influence of OSWP on grazing patterns will, however, vary by time of year, stocking rate, ecological site, species of grazer, and pasture size.

\section{MANAGEMENT IMPLICATIONS}

Our data suggest that implementation of OSWP tends to shift grazing pressure away from in-channel areas. This finding is significant because in-channel vegetation functions to filter sediments and to increase bank stability, thereby reducing stream sediment loads. Although OSWP proved to be effective in improving in-channel vegetation, as indicated by nNDVI, they must be placed appropriately to avoid the undesired outcome of piosphere extension into in-channel areas.

The nNDVI in piospheres near OSWP was considerably lower than the surrounding landscape, indicating that forage production in these areas was likely reduced or utilized. Land managers should avoid placement of OSWP near streams or other sensitive areas that can be degraded due to heavy grazing pressure and livestock use surrounding OSWP. Smaller pastures and more OSWP per pasture often result in smaller piospheres and less in-channel grazing pressure, by forcibly increasing the uniformity of grazing. New OSWP implementation programs could be ecologically and financially optimized by insuring the piospheres do not extend into in-channel/riparian areas, and that overlap between OSWP is reduced.

\section{ACKNOWLEDGMENTS}

This work was supported by the USDA Conservation Effects Assessment Project (CEAP), EPA 319 nonpoint source pollution program, and the USGS Climate and Land Use Program Research and Development Program. The authors thank the staff at the Buffalo Gap National Grassland, Wall, $\mathrm{SD}$, for assistance with field work and two anonymous reviewers for their insightful comments.

\section{LITERATURE CITED}

AndREW, M. H. 1988. Grazing impact in relation to livestock watering points. Trends in Ecology and Evolution 3:336-339.

Augustine, D. J., D. T. Booth, S. E. Cox, and J. D. Derner. 2012. Grazing intensity and spatial heterogeneity in bare soil in a grazing-resistant grassland. Rangeland Ecology \& Management 65:39-46.

BAlLEY, D. W. 2004. Management strategies for optimal grazing distribution and use of arid rangelands. Journal of Animal Science 82:E147-E153.

BallEY, D. W. 2005. Identification and creation of optimum habitat conditions for livestock. Rangeland Ecology \& Management 58:109-118.

Balley, D. W., M. R. Kell, and L. R. Rittenhouse. 2004. Research observation: daily movement patterns of hill climbing and bottom dwelling cows. Journal of Range Management 57:20-28.

Barker, W. T., and W. C. Whitman. 1988. Vegetation of the northern Great Plains. Rangelands 10:266-272.

Barnes, M. K., B. E. Norton, M. Maeno, and J. C. Malecheck. 2008. Paddock size and stocking density affect spatial heterogeneity of grazing. Rangeland Ecology \& Management 61:380-388.

Bastin, G. N., A. D. Sparrow, and G. Pearce. 1993. Grazing gradients in central Australian rangelands; ground verification of remote sensing-based approaches. The Rangeland Journal 15:217-233.

Bear, D. A., J. R. Russell, and D. G. Morrical. 2012. Physical characteristics, shade distribution, and tall fescue effects on cow temporal/spatial distribution in Midwestern pastures. Rangeland Ecology \& Management 65:401-408.

Chavez, P. S., JR. 1996. Image-based atmospheric corrections-revisited and improved. Photogrammetric Engineering and Remote Sensing 62:1025-1036.

DelCurto, T., M. Porath, C. T. Parsons, and J. A. Morrison. 2005. Management strategies for sustainable beef cattle grazing on forested rangelands in the Pacific Northwest. Rangeland Ecology \& Management 58:119-127.

Eckhardt, D. W., J. P. Verdin, AND G. R. LyFord. 1990 Automated update of an irrigated lands GIS using SPOT HRV imagery. Photogrammetric Engineering and Remote Sensing 56:1515-1522.

El Haju, M., A. Bégué, B. Lafrance, 0. Hagolle, G. Dedieu, and M. Rumeau. 2008. Relative radiometric normalization and atmospheric correction of a SPOT 5 time series. Sensors 8:2774-2791.

Fusco, M., J. Holechek, A. Tembo, A. Daniel, and M. Cardenas. 1995. Grazing influences on watering point vegetation in the Chihuahuan desert. Journal of Range Management 48:32-38.

George, M. R., R. D. Jackson, C. S. Boyd, and K. W. Tate. 2011. A. scientific assessment of the effectiveness of riparian management practices. In: D. D. Briske [ED.]. Conservation benefits of rangeland practices: assessment, recommendations, and knowledge gaps. Lawrence, KS, USA: USDA-NRCS. p. 213-252. 
Gillen, R. L., W. C. Krueger, and R. F. Miller. 1984. Cattle distribution on mountain rangeland in northeastern Oregon. Journal of Range Management 37:549-553.

Graz, F. P., M. E. Westbrooke, and S. K. Florentine. 2012. Modelling the effects of water-point closure and fencing removal: a GIS approach. Journal of Enviornemental Management 104:186-194.

Hart, R. H., J. Bissio, M. J. Samuel, and J. W. Waggoner, JR. 1993. Grazing systems, pasture size, and cattle grazing behavior, distribution, and gains. Journal of Range Management 46:81-87.

Hosten, P. E. 1995. Assessing the relative utility of models of vegetation dynamics for the management of sagebrush steppe rangelands [dissertation]. Logan, UT, USA: Utah State University. $210 \mathrm{p}$.

James, C. D., J. Landsberg, and S. R. Morton. 1999. Provision of watering points in the Australian arid zone: a review of effects on biota. Journal of Arid Environments 41:87-121.

Kawamura, K., T. Akiyama, H. Yokota, M. Tsutsumi, T. Yasuda, O. Watanabe, and S. Wang. 2005. Comparing MODIS vegetation indices with AVHRR NDVI for monitoring the forage quantity in Inner Mongolia grassland, China. Grassland Science 51:33-40.

LaunchBAuGh, K. L., AND L. D. HoweRy. 2005. Understanding landscape use patterns of livestock as a consequence of foraging behavior. Rangeland Ecology \& Management 58:99-108.

Matney, C. A. 2010. An assessment of plant community structure, herbivory, soils, and state-and-transition theory on a winterfat (Krascheninnikovia lanata [Pursh] A. D. J. Meeuse \& Smit) ecological site [dissertation]. Corvallis, OR, USA: Oregon State University. $276 \mathrm{p}$.

Moran, M. S., R. D. Jackson, P. N. Hart, R. J. Slater, S. F. Bartell, F. Biggar, D. I. Gellman, and R. P. Santer. 1990. Obtaining surface reflectance factors from atmospheric and view angle corrected SPOT-1 HRV data. Remote Sensing of Environment 32:203-214.

Pickup, G., G. N. Bastin, and V. H. Chewings. 1994. Remote-sensing-based condition assessment for nonequilibrium rangelands under large-scale commercial grazing. Ecological Applications 4:497-517.

Porath, M. L., P. A. Momont, T. DelCurto, N. R. Rimbey, J. A. Tanaka, and M. Mclnnis. 2002. Offstream water and trace mineral salt as management strategies for improved cattle distribution. Journal of Animal Science 80:346-356.
Sandercock, P. J., J. M. Hooke, and J. M. Mant. 2007. Vegetation in dryland river channels and its interaction with fluvial processes. Progress in Physical Geography 31:107-129.

Senft, R. L., L. R. Rittenhouse, and R. G. Woodmansee. 1985. Factors influencing patterns of cattle grazing behavior on shortgrass steppe. Journal of Range Management 38:82-87.

Shahriary, E., M. W. Palmer, D. J. Tongway, H. Azarnivand, M. Jafari, and M. Mohsen Saravi. 2012. Plant species composition and soil characteristics around Iranian piospheres. Journal of Arid Environments 82:106-114.

Smart, A. J., B. H. Dunn, P. S. Johnson, L. Xu, and R. N. Gates. 2007. Using weather data to explain herbage yield on three Great Plains plant communities. Rangeland Ecology \& Management 60:146-153.

THRASH, I. 1998. Impact of large herbivores at artificial watering points compared to that at natural watering points in Kruger National Park, South Africa. Journal of Arid Enivronments 38:315-324.

Thrash, I., and J. F. DerRy. 1999. The nature and modelling of piospheres: a review. Koedoe 42:73-95.

Toombs, T. P., AND M. G. RoberTs. 2009. Are natural resources conservation service range management investments working at cross-purposes with wildlife habitat goals on western United States rangelands? Rangeland Ecology \& Management 62:351-355.

Valentine, K. A. 1947. Distance from water as a factor in grazing capacity of rangeland. Journal of Forestry 45:749-754.

Vande Kamp, K., M. Rigge, N. H. Troelstrup, JR., A. J. Smart, and B. K. Wylie. 2013. Detecting channel riparian vegetation response to BMP implementation in ephemeral streams using SPOT HRV imagery. Rangeland Ecology \& Management 66:63-70.

Washington-Allen, R. A., T. G. Van Niel, R. Douglas Ramsey, and N. E. West. 2004. Remote sensing-based piosphere analysis. GIScience and Remote Sensing 41:136-154.

Wylie, B. K., D. J. Meyer, L. L. Tieszen, and S. Mannel. 2002. Satellite mapping of surface biophysical parameters at the biome scale over the North American grasslands: a case study. Remote Sensing of Environment 79:266-278. 